\title{
Optimization of key factors affecting hydrogen production from sugarcane bagasse by a thermophilic anaerobic pure culture
}

\author{
Zhicheng Lai, Muzi Zhu, Xiaofeng Yang, Jufang Wang and Shuang Li*
}

\begin{abstract}
Background: Hydrogen is regarded as an attractive future energy carrier for its high energy content and zero $\mathrm{CO}_{2}$ emission. Currently, the majority of hydrogen is generated from fossil fuels. However, from an environmental perspective, sustainable hydrogen production from low-cost lignocellulosic biomass should be considered. Thermophilic hydrogen production is attractive, since it can potentially convert a variety of biomass-based substrates into hydrogen at high yields.

Results: Sugarcane bagasse (SCB) was used as the substrate for hydrogen production by Thermoanaerobacterium aotearoense SCUT27/ $\Delta / d h$. The key parameters of acid hydrolysis were studied through the response surface methodology. The hydrogen production was maximized under the conditions of $2.3 \%$ of $\mathrm{H}_{2} \mathrm{SO}_{4}$ for $114.2 \mathrm{~min}$ at $115^{\circ} \mathrm{C}$. Using these conditions, a best hydrogen yield of $1.86 \mathrm{~mol} \mathrm{H}_{2} / \mathrm{mol}$ total sugar and a hydrogen production rate (HPR) of $0.52 \mathrm{~L} / \mathrm{L} \cdot \mathrm{h}$ were obtained from $2 \mathrm{~L} \mathrm{SCB}$ hydrolysates in a 5 - $\mathrm{L}$ fermentor, showing a superior performance to the results reported in the literature. Additionally, no obvious carbon catabolite repression (CCR) was observed during the fermentation using the multi-sugars as substrates.
\end{abstract}

Conclusions: Considering these advantages and theimpressive HPR, the potential of hydrogen production using T. aotearoense SCUT27/ $\Delta / d h$ is intriguing. Thermophilic, anaerobic fermentation using SCB hydrolysates as the medium by this strain would be a practical and eco-friendly process.

Keywords: Biohydrogen, Thermoanaerobacterium aotearoense SCUT27/A/dh, Non-sterilization, Sugarcane bagasse, Acid hydrolysate, Dark fermentation

\section{Background}

The depletion of fossil fuels has triggered concerns over the development of renewable energy sources. Although there are still some difficulties in hydrogen commercialization, such as high production costs, technical storage, and distribution [1], biohydrogen production is exhibiting perhaps the greatest potential as an alternative to fossil fuels [2] because of its clean, high energy content per unit of weight $(142 \mathrm{KJ} / \mathrm{g})$ and zero greenhouse gas emissions generated by oxidative combustion. Currently, most commercial hydrogen is obtained from steam reforming of hydrocarbons. High temperature electrolysis of alkaline solutions has been extensively developed in recent years, accounting for $4 \%$ of

\footnotetext{
* Correspondence: shuangli@scut.edu.cn

Guangdong Key Laboratory of Fermentation and Enzyme Engineering,

School of Bioscience and Bioengineering, South China University of

Technology, Panyu District, Guangzhou 510006, China
}

the current total hydrogen production [3]. However, all these processes are highly energy consuming and require high temperatures $\left(>850^{\circ} \mathrm{C}\right)$ [4], and thus are not sustainable. Biological methods are attractive because of their low energy requirements compared with those of chemical processes. The promising processes of biohydrogen production include light fermentation by photosynthetic bacteria and algae and dark fermentation by strictly or facultatively anaerobic bacteria. Since large amounts of lignocellulosic waste are made every year on earth [5], dark fermentation is a key technology for the production of hydrogen from agro-industrial by-products [1]. Various types of microorganisms can play a role in hydrogen formation by dark fermentation. However, thermophiles are energetically more favorable for hydrogen production, generating higher $\mathrm{H}_{2}$ yields and fewer undesirable by-products than mesophiles [6]. Moreover, strictly 
anaerobic thermophilic conditions seem to restrict contamination by other microorganisms [7].

Lignocellulosic biomass contains three main components: cellulose, hemicellulose, and lignin. Cellulose and hemicellulose are polysaccharides composed of sugar molecules, which could be used as a substrate for hydrogen production through dark fermentation. Sugarcane bagasse (hereafter SCB) offers numerous advantages with respect to its low ash content compared with other crop residues, such as rice straw and wheat straw, when used for bioprocessing purposes. Moreover, SCB is a richer solar energy carrier due to its higher yields in mass per unit area of cultivation and its annual regeneration capacity [8]. However, the lignin fractions in SCB form a formidable barrier to microbial digestion during fermentation. SCB pretreatment has been found useful in easing the difficulties of microorganisms' attack by enlarging the inner surface area of substrate particles. The pretreatment technology also fractionates SCB and results in partial solubilization and degradation of cellulose and hemicellulose [9]. Previous studies have reported on SCB pretreatment using either physical or chemical methods, such as acid [10-12], alkali [13], and steam [14-16]. However, it has been generally agreed that acid pretreatment is the method of choice in several model processes [17]. One of the most cost-effective pretreatments is to use dilute acid at moderate temperatures. Despite the fact that lignin cannot be removed by this process, its splitting renders a significant improvement in sugar yield compared to other processes.

After the pretreatment of SCB, the released fractions containing cellulose and hemicellulose must be converted to glucose and other monomeric sugars, which can be achieved by acid hydrolysis. Although high sugar recovery efficiency can be achieved through concentrated acid hydrolysis, problems associated with equipment corrosion and higher energy demand areunavoidable challenges. Also, dilute acid hydrolyzation consumes acid in small amounts, which implies that it is more friendly to the environment.

In our previous work, a new strain, Thermoanaerobacterium aotearoense SCUT27/ $/ d h$, was isolated and engineered which can generate a much higher hydrogen yield than most strains reported in the literature [18]. In this study, we used SCB hydrolysate to produce hydrogen with the SCUT27/ $\Delta l d h$ strain. Our preliminary study indicated that the SCUT27/ $\Delta l d h$ could utilize xylan and dextran as the sole carbon source to grow and release hydrogen without any enzyme addition. Furthermore, a related strain (LA1002) [19] could produce lactic acid efficiently under non-sterilized conditions without contamination. These facts encouraged us to explore hydrogen production with this strain using dilute acidhydrolyzed SCB as the substrate, without sterilization.
Herein, we have aimed to optimize the conditions for SCB hydrolysis to achieve more hydrogen with dilute sulfuric acid at relatively moderate temperatures through the use of the response surface methodology. The optimum conditions obtained were further confirmed in a larger batching process to produce hydrogen in a $5-\mathrm{L}$ fermentor containing $2 \mathrm{~L}$ hydrolysate.

\section{Results and discussion}

\section{Influence of carbon source on hydrogen production}

Prior to the utilization of sugarcane bagasse (SCB) hydrolysate for hydrogen production, a set of experiments was carried out in $125-\mathrm{mL}$ serum bottles with a working volume of $50 \mathrm{~mL}$. The fermentations were performed using a modified MTC medium [18] supplemented with different sugars or sugar mixtures as the carbon source to determine the cell growth and hydrogen production of $T$. aotearoense SCUT27/ $\Delta l d h$. The concentrations of sugars were at the same levels of $10 \mathrm{~g} / \mathrm{L}$. In the batch tests, the cell density and the produced hydrogen were determined, and all the experiments were carried out in triplicate.

Using the results from glucose as a control, the relative dry cell weight $(\mathrm{DCW})$ and hydrogen productivities were determined and are presented in Figure 1. In addition to glucose, SCUT27/ $\Delta l d h$ readily degraded xylose, mannose, cellobiose, fructose, galactose, maltose, beechwood xylan, and dextran to grow and produce hydrogen (Figure 1a). However, microorganisms could not efficiently grow using arabinose, lactose, and sucrose as the sole carbon source. In terms of a strong correlation between cell growth and hydrogen release [20], little hydrogen was detected using these sugars as the substrate with this strain. Among the different carbon sources examined, mannose achieved the highest hydrogen production, followed by cellobiose as a single carbon source. The final amount of hydrogen in the mixture was not distinctively different from that in the single sugar medium (Figure 1b). In addition, glucose, mannose, cellobiose, and xylose in a single sugar medium or in the mixed sugar medium were completely consumed after $24 \mathrm{~h}$ fermentation.

Generally, the fermentation of pentose (xylose, arabinose) is difficult for an efficient production of biofuels from lignocellulosic materials, because only a limited number of microorganisms can utilize pentose and other monosaccharides released from hemicelluloses (mannose, galactose) into bioproducts with a satisfactory yield and productivity. Although SCUT27/ $/ d h$ cannot utilize arabinose very effectively, it can convert xylose, mannose, and galactose to hydrogen efficiently, with more than $70 \%$ relative hydrogen productivity compared to that using glucose as the sole carbon source (Figure 1a). It is worth noting that SCUT27/ $\Delta l d h$ has a strong capability to utilize beechwood xylan and dextran as a 

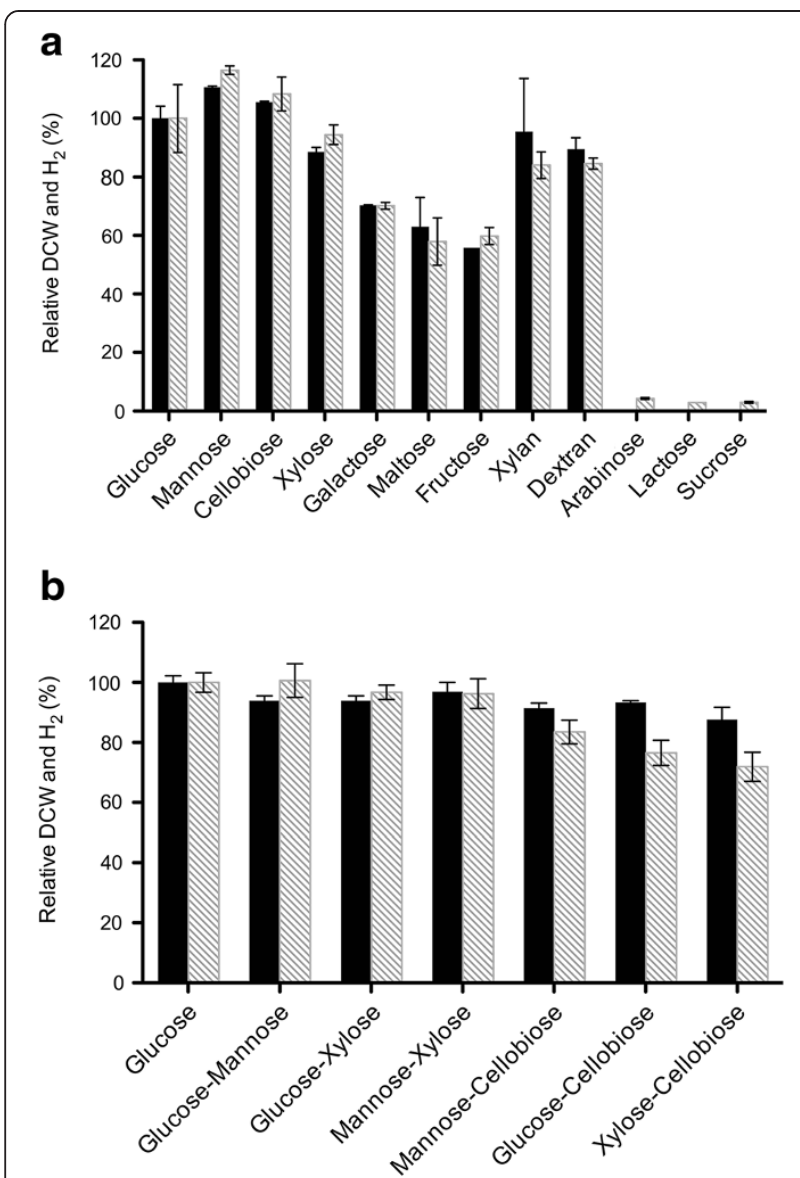

Figure 1 Comparison of relative DCWs (black bars) and hydrogen production (gray-shaded bars) for T. aotearoense SCUT27/D/dh using different sugars as carbon source. (a) Using single sugar as carbon source, (b) using sugar mixture as carbon source $(1: 1, w: w)$. Relative DCW and hydrogen production were calculated with respect to that using glucose as the sole carbon source. The error bars represent the standard deviation (SD) $(n=3)$. The data were collected and calculated after $24 \mathrm{~h}$ incubation at $55^{\circ} \mathrm{C}$, except those from beechwood xylan and dextran, which were recorded after $48 \mathrm{~h}$ cultivation. Experiments were carried out in triplicate.

single carbon source to support cell growth and hydrogen release without the addition of any cellulase or xylanase, because of its high level of cellulase and xylanase expression (unpublished data). In general practice, enzymatic hydrolysis is required for lignocellulosic biomass utilization in biofuel fermentation to obtain simple reducing sugars or monosaccharides [21]. The sugar utilization by the engineered strain of SCUT27/Aldh is considered very valuable for biohydrogen production using natural lignocellulosic materials as the feedstock.

\section{Effects of inhibitors on cell growth}

During the dilute acid pretreatment of SCB, many toxic compounds are produced or introduced which have potentially inhibitory effects on cell growth, thus posing a serious challenge for the feasibility of lignocellulosic biofuel production [22]. An understanding of the inhibitors' effects on $T$. aotearoense cell growth could help us to determine the further processing for hydrogen production after SCB hydrolysis.

Figure 2a shows the final cell density in $125-\mathrm{mL}$ serum bottles at $55^{\circ} \mathrm{C}$ for 12 or $24 \mathrm{~h}$, supplemented with different concentrations of inhibitors. The final DCW of SCUT27/ $\Delta l d h$ decreased as the acetic acid concentration increased over the range of 0 to $10 \mathrm{~g} / \mathrm{L}$, with a reduction of $90 \%$ at $10 \mathrm{~g} / \mathrm{L}$ acetic acid. However, the differences in the final cell mass under different acetic acid concentrations were narrowed when the cells were cultured at $55^{\circ} \mathrm{C}$ for $24 \mathrm{~h}$. This indicated that a high concentration of acetic acid could result in an extended lag phase. There was no obvious suppression of cell growth in concentrations of 0 to $1 \mathrm{~g} / \mathrm{L}$ for phenol and 0 to $1.6 \mathrm{~g} / \mathrm{L}$ for 2-furaldehyde (furfural), respectively (Figure $2 \mathrm{~b}$ and $\mathrm{c}$ ). However, the inhibition phenomenon became apparent at concentrations higher than $2 \mathrm{~g} / \mathrm{L}$ (phenol) and $3.2 \mathrm{~g} / \mathrm{L}$ (furfural). Experimental results showed that the inhibitory effect was not relieved by extending the incubation time to $24 \mathrm{~h}$. Furthermore, there was no substantial distinction among the final cell densities after $12 \mathrm{~h}$ or $24 \mathrm{~h}$ fermentation in the observed concentrations of 5-hydroxymethyl furfural (HMF) (Figure 2d). Actually, the maximum concentrations of furfural and HMF produced from the dilute acid hydrolysis of SCB in this study were lower than 0.8 and $0.2 \mathrm{~g} / \mathrm{L}$, respectively. Thus, no further investigation was applied to study the effects of these two inhibitors on the hydrogen production by SCUT27/ $\Delta l d h$.

\section{Acid hydrolysis of SCB}

In order to find the concentrations of released products from SCB hydrolysis, the treatments were carried out at different $\mathrm{H}_{2} \mathrm{SO}_{4}$ concentrations ranging from 0.2 to $4.0 \%$ at $115^{\circ} \mathrm{C}$ for different hydrolysis times varying from 30 to $150 \mathrm{~min}$. The concentrations of important components generated from the SCB solutions are shown in Figure 3. One can see that glucose and xylose are the main products, and the xylose concentration is always much higher than the glucose concentration because of the lower thermal stability of hemicellulose compared to that of cellulose $[23,24]$. The variation of arabinose and cellobiose in the range of $\mathrm{H}_{2} \mathrm{SO}_{4}$ concentration and hydrolysis time investigated was unremarkable. The concentrations of glucose and xylose increased with the extension of the reaction time. The highest glucose and xylose concentrations, 3.81 and $19.91 \mathrm{~g} / \mathrm{L}$, respectively, were observed at $150 \mathrm{~min}$ with $2.1 \% \mathrm{H}_{2} \mathrm{SO}_{4}$ treatment. Under these conditions, $1.78 \mathrm{~g} / \mathrm{L}$ arabinose, $1.53 \mathrm{~g} / \mathrm{L}$ cellobiose, $3.58 \mathrm{~g} / \mathrm{L}$ acetic acid, and $1.29 \mathrm{~g} / \mathrm{L}$ phenolic compounds were achieved.

It needs to be stressed that an increase in acid concentration did not always result in an increase in glucose/ xylose production. Generally speaking, increasing the acid 

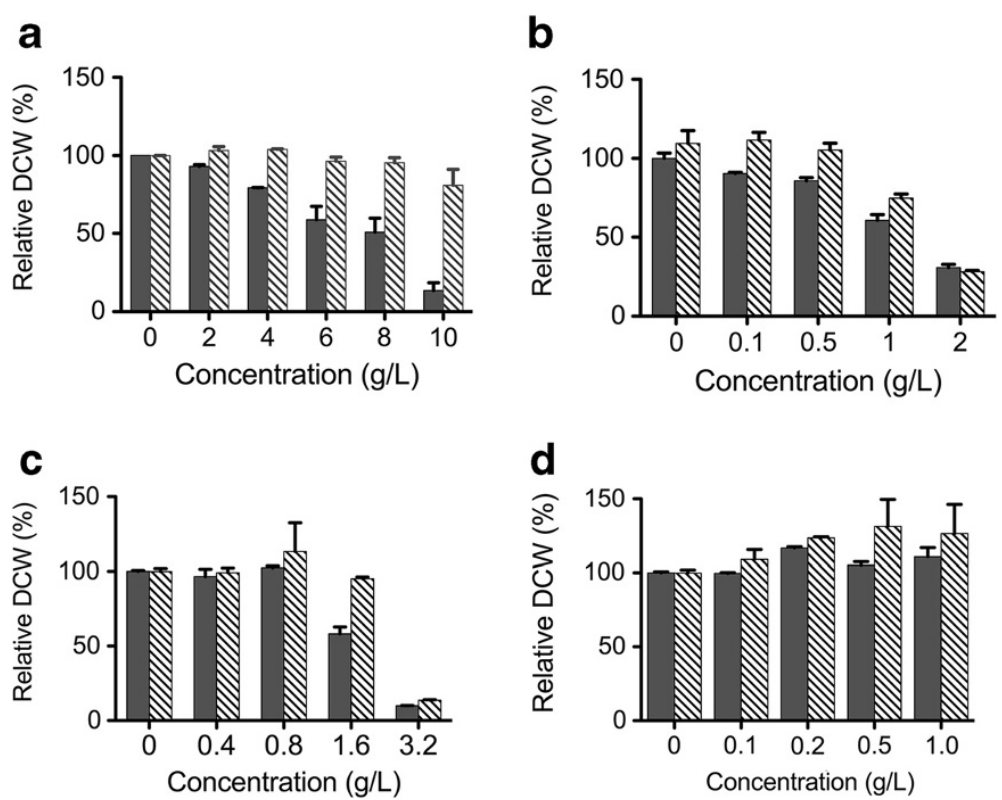

Figure 2 Cell growth of $T$. aotearoense SCUT27/A/dh after different incubation time at $55^{\circ} \mathrm{C}$ in the modified MTC medium supplemented with different concentrations of toxic agents. Fermentation time of $12 \mathrm{~h}$ is showed as black bars and $24 \mathrm{~h}$ is presented as gray-shaded bars. (a) acetic acids, (b) phenols (c) furfurals and (d) 5-hydroxymethyl furfural. Experiments were performed in triplicate.

concentration allows for a stronger reaction for breaking down the chemical bonds of cellulosic biomass, therefore yielding higher concentrations of hydrolyzed products [11]. However, further conversion of sugars to other substances, such as furfural and HMF, could potentially occur when excess acid is added [25]. The higher concentrations of furfural and HMF have been reported to damage microorganisms and inhibit cell growth and metabolism [22]. Our results showed the same trend; the sugar concentration was significantly decreased accompanied by an increase of furfural and HMF using 4.0\% $\mathrm{H}_{2} \mathrm{SO}_{4}$. For the highest concentrations of furfural and HMF in the SCB hydrolysate below the lower limit of the toxic effect, no relevant data were presented in Figure 3.

For higher concentrations of sugars released, often with higher inhibitor generation, we define the hydrolysis efficiency $(E)$ to inspect the optimum condition for the acid hydrolysis of SCB (Table 1). The $E$ values increased from 1.59 to 3.35 when the reaction time changed from $30 \mathrm{~min}$ to $150 \mathrm{~min}$ at the lower $\mathrm{H}_{2} \mathrm{SO}_{4}$ concentration of $0.2 \%(v / v)$. Not surprisingly, an excess degree of acid hydrolysis, from a higher $\mathrm{H}_{2} \mathrm{SO}_{4}$ concentration or a longer acid hydrolysis time, led to a decrease of the $E$ value. In terms of green chemistry and cost reduction, we prefer to keep the acid concentration as low as possible, and to shorten the reaction time as much as possible. Based on the above considerations, conditions of $2.1 \%(v / v)$ of $\mathrm{H}_{2} \mathrm{SO}_{4}$ for $90 \mathrm{~min}$ of hydrolysis were arguably the best, achieving the highest $E$ ratio of 6.60 with a total amount of sugars of $24.88 \mathrm{~g} / \mathrm{L}$ and an amount of inhibitors of $6.6 \mathrm{~g} / \mathrm{L}$.

\section{Optimization of hydrogen production from SCB hydrolysates}

Our preliminary study revealed that $T$. aotearoense SCUT27/ $\Delta l d h$ could grow and produce hydrogen in the SCB hydrolysate without any sterilization steps. Thus, in this study, all the biohydrogen production from SCB hydrolysates by SCUT27/ $l d h$ was performed under nonsterilized anaerobic fermentation, which simplified the pretreatment process greatly. In order to identify if the cultured organisms after non-sterilized fermentation were still the strain $T$. aotearoense SCUT27/ $l d h$, the $16 \mathrm{~S}$ rDNA gene was amplified, using the genomic DNA prepared from the fermentation broth as template, and then sequenced. The PCR products were cloned into the $\mathrm{pMD}^{\mathrm{Tm}} 18-\mathrm{T}$ vector and then transformed into Escherichia coli DH5 $\alpha$ competent cells. Five single colonies randomly selected were isolated, and the $16 \mathrm{~S}$ rDNA gene was sequenced. Alignment results showed more than $99 \%$ similarity in gene sequence, which confirmed that the screened samples were the targeted microorganisms (see Additional file 1).

Table 2 shows the level and range of two parameters investigated, the concentration of sulfuric acid and the treatment time. All parameters were taken at a central coded value considered as zero and studied at three different levels $(-1,0$, and +1$)$. In this case, a three-level factorial design resulting in a total number of 13 experiments was employed to fit the second-order polynomial model according to a design by Design-Expert 8.0. The statistical combinations of the critical parameters along with the maximum observed and predicted hydrogen 


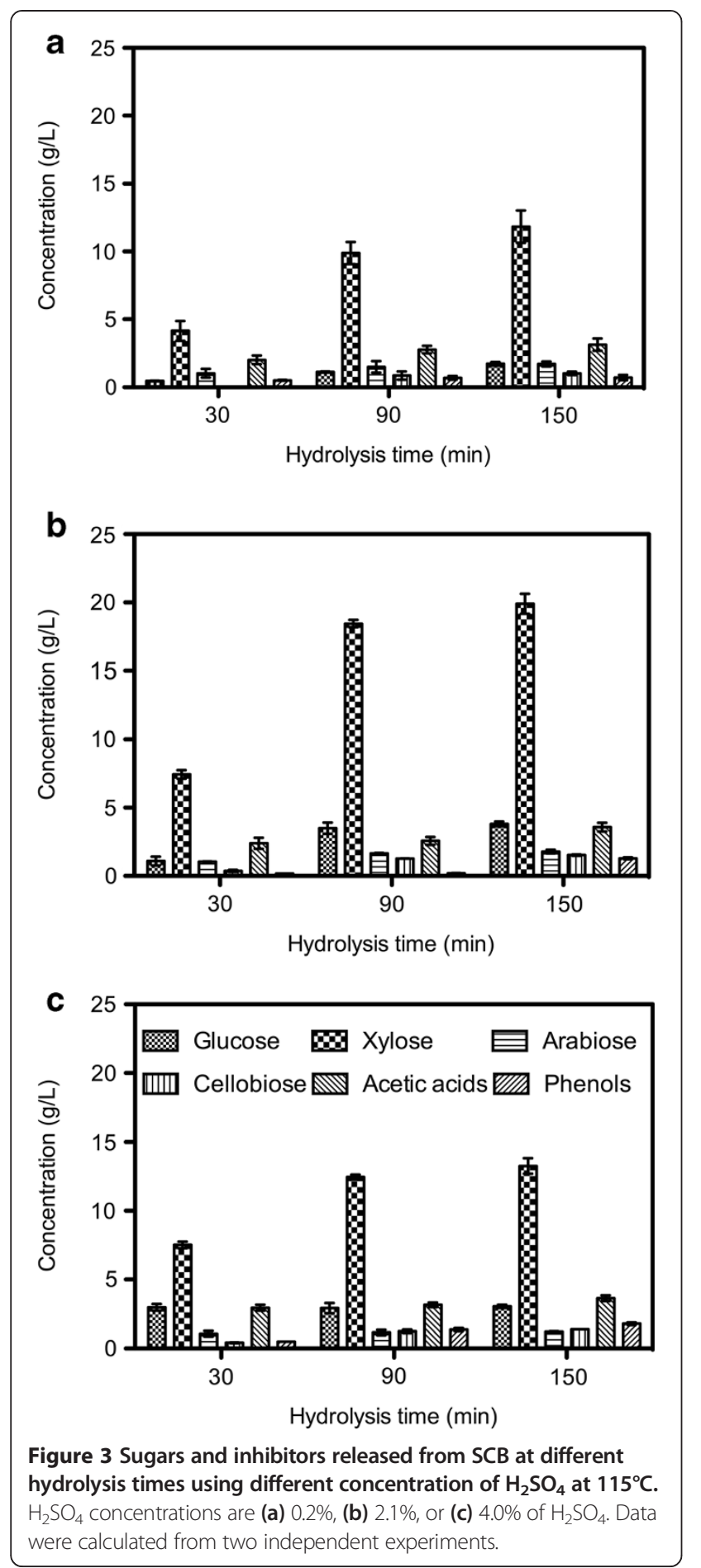

production are also listed in Table 2. These predicted values were close to the observed ones in all sets of experiments. A highest hydrogen output of $149.54 \mathrm{~mL}$ and a lowest oneof $28.05 \mathrm{~mL}$ were observed. Two regression equations, Equation 1a for coded values and Equation $1 \mathrm{~b}$ for actual experimental values, which are analogous to Equation 3, showed the hydrogen $(Y)$ as a function of the
Table 1 Comparision of SCB hydrolyzed at different $\mathrm{H}_{2} \mathrm{SO}_{4}$ concentrations for different reaction times

\begin{tabular}{lllll}
\hline $\begin{array}{l}\mathbf{H}_{2} \mathbf{S O}_{4} \\
(\%, \mathbf{v} / \mathbf{v})\end{array}$ & $\begin{array}{l}\text { Incubation } \\
\text { time }(\mathbf{m i n})\end{array}$ & $\begin{array}{l}\text { Total sugar }^{\mathbf{a}} \\
(\mathbf{g} / \mathbf{L})\end{array}$ & $\begin{array}{l}\text { Total } \\
\text { inhibitor }\end{array}$ \\
\hline 0.2 & 30 & 5.66 & 2.55 & Efficiency $^{\mathbf{c}}(\mathbf{E})$ \\
& 90 & 13.40 & 3.48 & 1.59 \\
& 150 & 16.32 & 3.87 & 2.99 \\
2.1 & 30 & 9.96 & 2.58 & 3.35 \\
& 90 & 24.88 & 2.77 & 2.78 \\
& 150 & 27.30 & 4.87 & 6.60 \\
4.0 & 30 & 11.99 & 3.44 & 4.60 \\
& 90 & 17.76 & 4.53 & 3.70 \\
& 150 & 18.89 & 5.43 & 2.94 \\
\hline
\end{tabular}

${ }^{a}$ Total sugar $=$ glucose + xylose + arabinose + cellobiose.

${ }^{\mathrm{b}}$ Total inhibitor = acetic acid + phenol compounds.

${ }^{c} E=$ total sugar $/(1+$ total inhibitor $)$ [23].

test variables $X_{1}\left(\mathrm{H}_{2} \mathrm{SO}_{4}\right.$ concentration) and $X_{2}$ (treatment time):

$$
\begin{aligned}
Y_{\text {coded }}= & 135.15+11.11 X_{1}+28.27 X_{2}-6.12 X_{1} X_{2} \\
& -41.05 X_{1}^{2}-34.20 X_{2}^{2} \\
Y_{\text {actual }}= & -56.80+58.44 X_{1}+2.29 X_{2}-0.05 X_{1} X_{2} \\
& -11.37 X_{1}{ }^{2}-9.50 * 10^{-3} X_{2}{ }^{2}
\end{aligned}
$$

\begin{tabular}{|c|c|c|c|c|c|c|c|}
\hline \multirow[t]{2}{*}{ Std } & \multirow[t]{2}{*}{ Type $^{\text {b }}$} & \multicolumn{2}{|c|}{$\begin{array}{l}\text { Concentration } \\
\text { (\%) }\end{array}$} & \multicolumn{2}{|l|}{$\begin{array}{l}\text { Time } \\
(\min )\end{array}$} & \multicolumn{2}{|c|}{ Hydrogen $(\mathrm{mL})$} \\
\hline & & Code & $x_{1}$ & Code & $x_{2}$ & Experimental & Predicted \\
\hline 1 & $\mathrm{~F}$ & -1 & 0.2 & -1 & 30 & 28.05 & 14.38 \\
\hline 2 & CE & 0 & 2.1 & -1 & 30 & 46.90 & 72.67 \\
\hline 3 & $\mathrm{~F}$ & 1 & 4.0 & -1 & 30 & 60.95 & 48.85 \\
\hline 4 & CE & -1 & 0.2 & 0 & 90 & 66.45 & 82.98 \\
\hline 5 & C & 0 & 2.1 & 0 & 90 & 141.05 & 135.15 \\
\hline 6 & CE & 1 & 4.0 & 0 & 90 & 91.80 & 105.20 \\
\hline 7 & $\mathrm{~F}$ & -1 & 0.2 & 1 & 150 & 86.05 & 83.18 \\
\hline 8 & CE & 0 & 2.1 & 1 & 150 & 125.05 & 129.22 \\
\hline 9 & $\mathrm{~F}$ & 1 & 4.0 & 1 & 150 & 94.45 & 93.15 \\
\hline 10 & C & 0 & 2.1 & 0 & 90 & 145.21 & 135.15 \\
\hline 11 & C & 0 & 2.1 & 0 & 90 & 149.54 & 135.15 \\
\hline 12 & C & 0 & 2.1 & 0 & 90 & 138.09 & 135.15 \\
\hline 13 & C & 0 & 2.1 & 0 & 90 & 131.78 & 135.15 \\
\hline
\end{tabular}

Table 2 Three-level factorial experimental design with experimental and predicted values using different concentrations of $\mathrm{H}_{2} \mathrm{SO}_{4}$ and treatment times ${ }^{\mathrm{a}}$

${ }^{a}$ Design part was derived from the software Design-Expert 8.0.

${ }^{\mathrm{b}} \mathrm{F}=$ Factorial, $\mathrm{CE}=$ CentEdge, $\mathrm{C}=$ Center. 
Where $Y$ is the hydrogen production from SCB hydrolysates expressed in microliters $(\mathrm{mL})$.

A statistical analysis, such as analysis of variance (ANOVA), is essential to test the significance and adequacy of the model. The ANOVA of the quadratic regression model demonstrated that the model is highly significant, evidenced by an $F$-value equal to 13.97 in the Fisher $F$-test and a very low probability value $(P$-value $=0.0016)$ (Table 3$)$ [26].

The two- and three-dimensional contour plots of the variation of hydrogen production with $\mathrm{H}_{2} \mathrm{SO}_{4}$ concentration and treatment time (Figure 4) are elliptical and have clear elongated diagonals, indicating significant interactive effects on hydrogen production $(Y)$ between the two independent variables. Figure 4b has clear peaks, and the corresponding contour plot has clear maxima, indicating that maximum hydrogen could be achieved inside the design boundaries. The results depicted that the predicted $141.43 \mathrm{~mL}$ of maximum hydrogen production using SCB as substrate was found at $2.3 \%$ of $\mathrm{H}_{2} \mathrm{SO}_{4}$ and a treatment time of $114.2 \mathrm{~min}$. Validation experiments (carried out in triplicate) were conducted to confirm the predicted optimal conditions, and gave a mean hydrogen production of $143.51 \pm 2.29 \mathrm{~mL} \mathrm{H}_{2}$, very close to the predicted value. The results suggested a strong correlation between cumulative hydrogen produced and $E$

Table 3 ANOVA for hydrogen production by $T$. aotearoense SCUT27/DIdh with SCB hydrolysates as substrate ${ }^{a}$

\begin{tabular}{|c|c|c|c|c|c|c|}
\hline Factors & $\begin{array}{l}\text { Sum of } \\
\text { squares }\end{array}$ & $\begin{array}{l}\text { Degrees of } \\
\text { freedom }\end{array}$ & $\begin{array}{l}\text { Mean } \\
\text { square }\end{array}$ & $\begin{array}{l}F \text { - } \\
\text { value }\end{array}$ & $\begin{array}{l}P \text { - } \\
\text { value }\end{array}$ & \\
\hline Model & 18368.05 & 5 & 3673.61 & 13.97 & 0.0016 & significant \\
\hline$X_{1}$ & 740.37 & 1 & 740.37 & 2.82 & 0.1373 & \\
\hline$x_{2}$ & 4796.85 & 1 & 4796.85 & 18.24 & 0.0037 & \\
\hline$X_{1} X_{2}$ & 150.06 & 1 & 150.06 & 0.57 & 0.4747 & \\
\hline$X_{1}^{2}$ & 4654.76 & 1 & 4654.76 & 17.70 & 0.0040 & \\
\hline$X_{2}^{2}$ & 3230.99 & 1 & 3230.99 & 12.29 & 0.0099 & \\
\hline Residual & 1840.87 & 7 & 262.98 & & & \\
\hline $\begin{array}{l}\text { Lack of } \\
\text { fit }\end{array}$ & 1656.83 & 3 & 552.28 & 12.00 & 0.0181 & significant \\
\hline $\begin{array}{l}\text { Pure } \\
\text { error }\end{array}$ & 184.04 & 4 & 46.01 & & & \\
\hline Cor total & 20208.92 & 12 & & & & \\
\hline
\end{tabular}

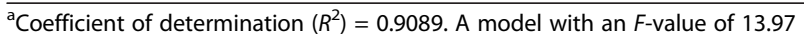
implies that the model is significant. There is only a $0.16 \%$ chance that a model $F$-value this large could occur due to noise. Values of "Prob $>F$ " less than 0.0500 indicate that model terms are significant. In this case $B, A 2, B 2$ are significant model terms. The "Lack of fit $F$-value" of 12.00 implies that the lack of fit is significant. There is only a $1.81 \%$ chance that a lack of fit $F$-value this large could occur due to noise. The "Pred R-Squared" of 0.3684 is not as close to the "Adj R-Squared" of 0.8438 as one might normally expect. This may indicate a large block effect or a possible problem with a model and/or data. Things to consider are model reduction, response transformation, and outliers, among others. "Adeq Precision" measures the signal-to-noise ratio. A ratio greater than 4 is desirable. A ratio of 10.962 indicates an adequate signal. This model can be used to navigate the design space.
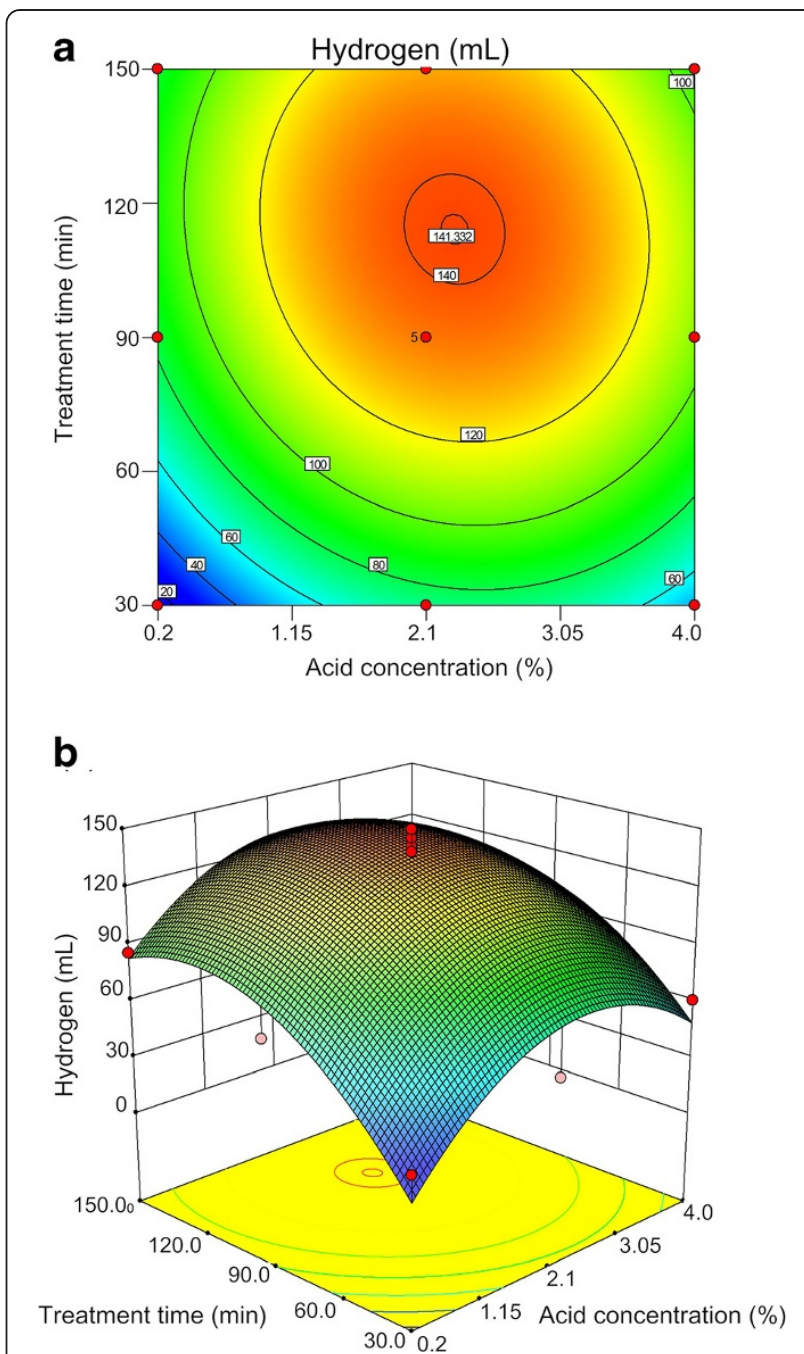

Figure 4 Different plots of quadratic model of the effects of acid concentration and reaction time on the $\mathrm{H}_{2}$ production. (a) two-dimensional contour plot and (b) three-dimensional diagram. The predicted optimum hydrogen production using sugarcane bagasse as the substrate was found at $2.3 \% \mathrm{H}_{2} \mathrm{SO}_{4}$ and $114.2 \mathrm{~min}$.

value, implying the importance of the relative amount of inhibitor to sugar concentration in hydrogen production.

Residual plots of the model were randomly distributed without any trends (not shown), validating the quadratic models.

\section{Hydrogen production from sugarcane bagasse hydrolysate}

The batch culture profiles clearly showed that $T$. aotearoense SCUT27/ $\Delta l d h$ could grow and produce hydrogen effectively in a 5-L fermentor containing $2 \mathrm{~L}$ non-sterilized SCB hydrolysate. Glucose and cellobiose were depleted at $6 \mathrm{~h}$. Xylose was almost completely utilized after $16 \mathrm{~h}$ cultivation, while arabinose was slowly consumed during the fermentation process (Figure 5a). 


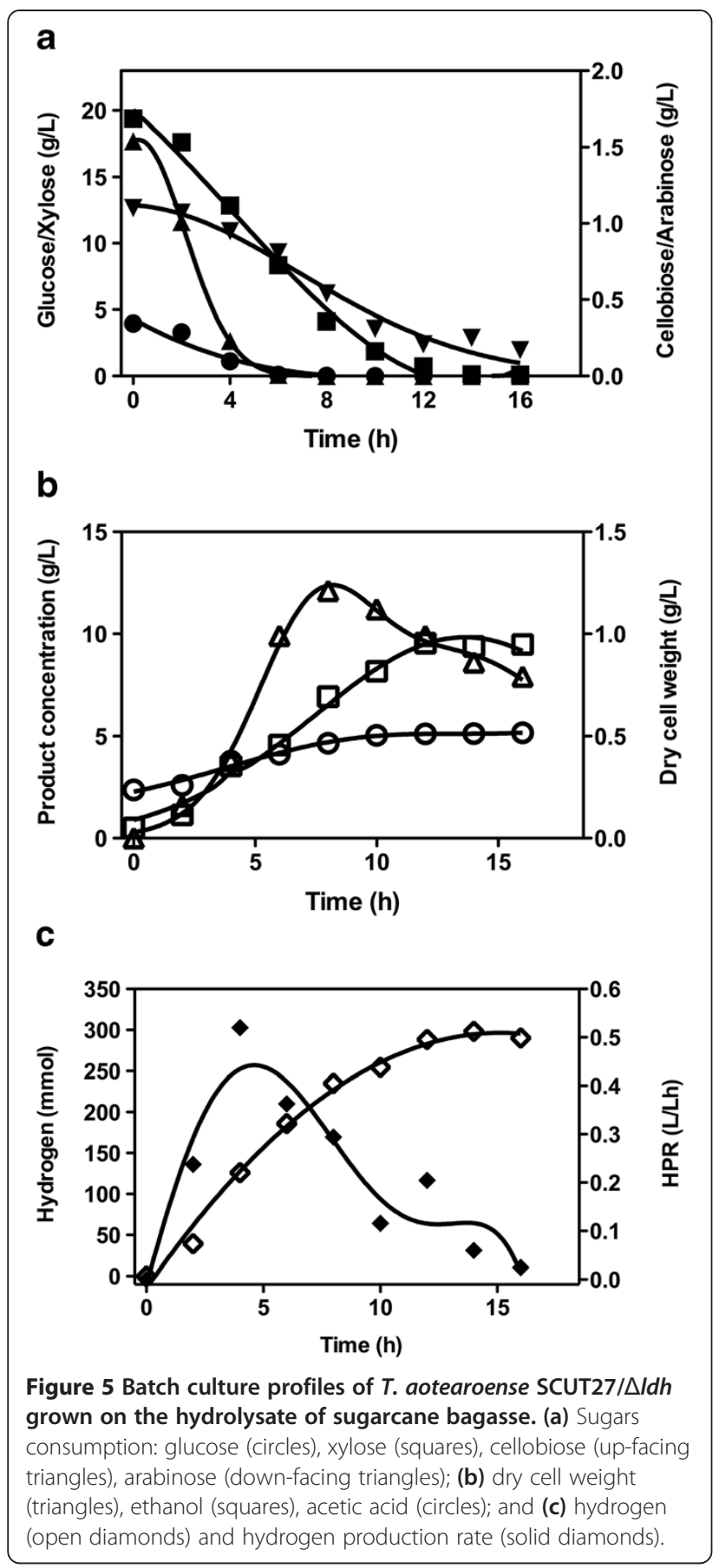

As shown in Figure 5b, the concentrations of the main liquid products, ethanol and acetic acid, increase with time and level off after $12 \mathrm{~h}$ incubation. The highest ethanol concentration reached $9.54 \mathrm{~g} / \mathrm{L}$ with a yield of $0.42 \mathrm{~g} / \mathrm{g}$ total sugars. The DCW climbed to $1.16 \mathrm{~g} / \mathrm{L}$ at $8 \mathrm{~h}$ fermentation and then slowly declined. A small amount of acetic acid was produced at a maximum concentration of $5.12 \mathrm{~g} / \mathrm{L}$ at the end of fermentation; however $2.37 \mathrm{~g} / \mathrm{L}$ acetic acid originated from the acid pretreatment of SCB.
T. aotearoense SCUT27/ $\Delta l d h$ can produce hydrogen efficiently using SCB hydrolysate (Figure $5 \mathrm{c}$ and Table 4). The final amount of hydrogen reached a value of $298.4 \mathrm{mmol}$. An average hydrogen molar yield of $1.86 \mathrm{~mol} \mathrm{H}_{2} / \mathrm{mol}$ total sugar was obtained at the late fermentation period by this engineered strain. The achieved hydrogen yield was in the average range of previous reports (Table 4). Moreover, the HPR values increased over time in the initial stage of fermentation and decreased after the maximum HPR of $0.52 \mathrm{~L} / \mathrm{L} \cdot \mathrm{h}$ obtained at the point of $4 \mathrm{~h}$ fermentation. Most thermophiles are able to hydrolyze various polysaccharides and ferment the released hexoses and pentoses to $\mathrm{H}_{2}$ with yields close to the theoretical maximum of $4 \mathrm{~mol} \mathrm{H}_{2} / \mathrm{mol}$ hexose [6]. Nielet al. [27] reported a hydrogen yield of $3.33 \mathrm{~mol} / \mathrm{mol}$ hexose using either Caldicellulosiruptor saccharolyticus on sucrose $\left(70^{\circ} \mathrm{C}\right)$ or Thermotogaelfii on glucose $\left(65^{\circ} \mathrm{C}\right)$, and similar yields were achieved by Mars et al. using hydrolyzed potato steam peels as the substrate [28]. Even so, ithas been pointed out that a drawback of thermophiles is that the HPR is relatively low, generally ranging from 0.01 to $0.2 \mathrm{~L} / \mathrm{L} \cdot \mathrm{h}$. However, the maximum $\mathrm{HPR}$ achieved by SCUT27/ $\Delta l d h$ was much higher than those previously reported (Table 4). The performance of hydrogen production by SCUT27/ $\Delta l d h$ using SCB hydrolysates in this study revealed a promising biohydrogen production process from cellulosic biomass.

It is important to note that all the sugar utilization (xylose, cellobiose, and arabinose) in the cultivation was started with glucose consumption at the initial stage, indicating that carbon catabolite repression (CCR) was not obvious for the strain. The rapid consumption of xylose with glucose might be the main reason for the high HPR by SCUT27/ $\Delta l d h$ using SCB hydrolysates as substrate.

$\mathrm{CCR}$ is a tenacious bottleneck in the microbial production of bio-based chemicals from lignocellulosederived sugar mixtures. A preferential sugar uptake (for example, glucose), accompanied by the blocking of less preferred sugars, leads to one of the major barriers in increasing the yield and productivity of the fermentation process [37]. Hence, the discovery of a strain with the capacity to co-utilize all of the sugars derived from biomass is one of the main tasks in cellulosic energy production [38]. Although several genetic and evolutionary engineering approaches achieved efficient pentose utilization in some industrial cell factories, such as those using Zymomonas mobilis [39] and Saccharomyces cerevisiae [40], CCR still remains a major bottleneck. However, it is encouraging that SCUT27/ $\Delta l d h$ could consume hexose and pentose almost simultaneously in the SCB hydrolysate, as this could be advantageous in improving productivity and shortening fermentation time in lignocellulosic fuel production. In particular, the cellobiose utilizing capability of SCUT27/ $\Delta l d h$ would help to reduce the need for 
Table 4 Comparison of hydrogen production using various types of low-cost materials as substrate

\begin{tabular}{|c|c|c|c|c|c|c|}
\hline Microorganism & $\begin{array}{l}\text { Cultivation } \\
\text { method }\end{array}$ & Temperature & Substrate & $\begin{array}{l}\mathrm{H}_{2} \text { yield } \\
\text { ( } \mathrm{mol} \mathrm{H}_{2} / \mathrm{mol} \text { hexose) }\end{array}$ & $\begin{array}{l}\text { HPR } \\
(L / L \cdot h)\end{array}$ & Ref. \\
\hline Clostridium paraputrificum M-21 & Batch & 45 & Corn fiber & 1.1 & - & [29] \\
\hline C. bifermentans & Batch & 35 & Wastewater sludge & $2.1^{\mathrm{a}}$ & - & {$[30]$} \\
\hline Caldicellulosiruptor saccharolyticus & Batch & 70 & Hydrolyzed potato steam peels & 3.4 & $0.26^{d}$ & {$[28]$} \\
\hline C. saccharolyticus & Batch & 70 & Paper sludge hydrolysate & 3.84 & 0.12 & {$[31]$} \\
\hline Thermotoga neapolitana & Batch & 80 & Hydrolyzed potato steam peels & 3.3 & $0.20^{\mathrm{d}}$ & [28] \\
\hline Klebsiella oxytoca HP1 & Continuous & 38 & Bagasse & $1.60^{\mathrm{b}}$ & 0.35 & [32] \\
\hline Clostridium butyricum (immobilized) & Batch & 37 & Sugarcane juice & 1.52 & $0.14^{d}$ & [33] \\
\hline NA & Batch & 60 & Cow manure & $10.25^{c}$ & 0.02 & [34] \\
\hline Seed sludge & Batch & 35 & Pineapple waste & 1.83 & $0.08^{e}$ & [35] \\
\hline Seed sludge & Batch & $30-32$ & Sweet sorghum syrup & 2.22 & 0.05 & [4] \\
\hline C. butyricum & Batch & 37 & SCB hydrolysate & 1.73 & 0.07 & {$[11]$} \\
\hline $\begin{array}{l}\text { Thermoanaerobacterium } \\
\text { thermosaccharolyticum W16 }\end{array}$ & Batch & 60 & Corn stover & - & $0.25^{d}$ & [36] \\
\hline T. aotearoense SCUT27/ $/ d h$ & Batch & 55 & SCB hydrolysate & 1.86 & 0.52 & This study \\
\hline
\end{tabular}

${ }^{\mathrm{a}} \mathrm{mmol} \mathrm{H} / \mathrm{g}$ COD.

${ }^{b} \mathrm{mmol} \mathrm{H}_{2} / \mathrm{g}$ solid.

$\mathrm{c}_{\mathrm{mL} \mathrm{H}} / \mathrm{g}$ volatile solid.

dObtained by calculation from reported data.

${ }^{\mathrm{e}} \mathrm{L} \mathrm{H}_{2} / \mathrm{g}$ volatile solid/h.

additional saccharifying enzymes used in the hydrolysis of lignocellulose $[19,41]$.

\section{Conclusions}

This study demonstrated that a sulfuric acid hydrolysate of SCB was suitable for producing hydrogen by $T$. aotearoense SCUT27/Dldh due to the main compounds of $x y-$ lose and glucose and low concentrations of inhibitors. The variations in acid concentration and treatment time affected the hydrolysis efficiency and the hydrogen production. The optimum conditions were found to be $2.3 \%$ $\mathrm{H}_{2} \mathrm{SO}_{4}$ and 114.2 min reaction time at $115^{\circ} \mathrm{C}$. Research with larger batches in 5-L fermentation tanks finally produced $298.40 \mathrm{mmol}$ hydrogen with an average molar yield of $1.86 \mathrm{~mol} \mathrm{H}_{2} / \mathrm{mol}$ total sugar and a maximum HPR of $0.52 \mathrm{~L} / \mathrm{L} \cdot \mathrm{h}$, respectively. Also, there was no obvious CCR, which would be beneficial for higher hydrogen production and shorter retention time. All the thermophilic hydrogen performance results using non-sterilized SCB hydrolysates as substrate showed a favorable comparison with the results reported in the literature for sterilized fermentation. In particular, the higher HPR might give a more competitive edge for a process using inexpensive raw materials. Considering the low cost of $\mathrm{SCB}$, the relatively moderate operation conditions, and the fact that there is no need for sterilization, hydrogen production by SCUT27/ $\Delta l d h$ from the dilute acid treatment of SCB might be practically and economically attractive for industrial mass production.

\section{Methods}

\section{Microorganism}

The engineered strain of $T$. aotearoense SCUT27/ $\Delta l d h$ was obtained by our group in a previous work [18]. Single colonies were selected and cultured to the exponential phase and subsequently maintained in $10-\mathrm{mL}$ crimp-sealed anaerobic tubes in $25 \%$ glycerol and $75 \%$ growth medium at $-80^{\circ} \mathrm{C}$ for long-term conservation. The cultures recovered from glycerol stocks were activated by transferring $2 \mathrm{~mL}$ of the stock culture into $4 \mathrm{~mL}$ of fresh modified MTC medium [18]. The serum tube was flushed with nitrogen to create anaerobic conditions and cultured at $55^{\circ} \mathrm{C}$ for about $12 \mathrm{~h}$ to reach an optical density $\left(\mathrm{OD}_{600}\right)$ of 0.8 . Then the cells were further enriched by inoculating $10 \% v / v$ of the previous culture into $12 \mathrm{~mL}$ fresh MTC medium and incubated at the given conditions to an $\mathrm{OD}_{600}$ of 1.0 prior to inoculum.

\section{SCB pretreatment}

The SCB used in this study was obtained locally from the Guangzhou Sugarcane Industry Research Institute (Guangzhou, China). The SCB was air dried until the weight was constant. Then it was milled, screened through a $0.3-\mathrm{mm}$ sieve, homogenized in a single lot, and kept at $4^{\circ} \mathrm{C}$ until use. The SCB consists of $(w / v)$ glucan, $39.50 \pm$ $0.66 \%$; xylan, $19.77 \pm 0.03 \%$; araban, $2.02 \pm 0.25 \%$; klason lignin $21.04 \pm 0.01 \%$; acid-soluble lignin, $4.89 \pm 0.21 \%$; ash, $5.69 \pm 0.01 \%$; moisture, $6.85 \pm 0.01 \%$ and other components. 


\section{Acid hydrolysis}

According to procedures for the acid hydrolysis of SCB $[10,23]$, the dried SCB was hydrolyzed by $0.2 \%, 2.1 \%$, and $4.0 \%(v / v)$ of sulfuric acid in an autoclave at $115^{\circ} \mathrm{C}$. The time of the hydrolysis was controlled at 30, 90, and $150 \mathrm{~min}$. For all conditions we used a liquid/solid ratio (LSR) of $15 \mathrm{~mL}$ liquid/g dry weight of SCB (modified from [11]). The solution was filtered through Whatman ${ }^{\bullet}$ filter papers, and the filtrate was adjusted to neutral using solid calcium hydroxide, followed by a centrifugation at 10,000 rpm for $20 \mathrm{~min}$ (Thermo Scientific Sorvall Legend RT Plus). The supernatant was adjusted to a $\mathrm{pH}$ of 6.8 with concentrated hydrochloric acid. Then the samples were analyzed for sugars and inhibitors by high performance liquid chromatography (HPLC). The hydrolysates from the SCB were added with the essential components of the buffer system, the nitrogen source, inorganic salt, and trace elements in the MTC medium recipes [18] and used as substrates to produce hydrogen by SCUT27/ $l d h$.

\section{Optimization of acid hydrolysis for hydrogen production} A response surface methodology (RSM) with a threelevel factorial design (miscellaneous) was used as the experimental design model to optimize the key process parameters for enhanced hydrogen production. For two factors, the miscellaneous design offers some advantages, asit requires fewer experimental runs and allows efficient estimation ofquadratic surfaces, which usually works well for the optimization of the response within the region of the observation space $[42,43]$. For statistical calculations, the variables $X_{i}$ (the uncoded value of the $i$ th independent variable) were coded as $x_{i}$ (the coded value of the $i$ th independent variable) according to the following equation:

$$
x_{i}=\frac{X_{i}-X_{i}^{*}}{\Delta X_{i}}
$$

where $X_{i}^{*}$ is the value of $X_{i}$ at the center point, and $\Delta X_{i}$ is the step change value.

In the present study, the levels of the variables and the experimental design (according to Design-Expert 8.0) are shown in Table 2. The hydrogen production amounts in volume were associated with simultaneous changes in sulfuric acid concentration $(0.2,2.1$, and $4.0 \%$ ) and the hydrolysis time (30, 90, and $150 \mathrm{~min}$ ) of SCB. Accordingly, 13 experiments determined with the miscellaneous design were carried out for building quadratic models, with four replications of the center points to estimate experimental errors. The experimental data obtained from the miscellaneous design model experiments were represented in the following equation to predict the optimal conditions:

$$
Y=b_{0}+\sum_{i=1}^{n} b_{i} X_{i}+\sum_{i=1}^{n} b_{i i} X_{i}^{2}+\sum_{i=1}^{n-1} \sum_{j=i+1}^{n} b_{i j} X_{i} X_{j}+e_{i}
$$

where $X_{i}$ are the input variables, which influence the response variable $Y, b_{0}$ is the offset term, $b_{i}, b_{i i}$, and $b_{i j}$ are the first-order, quadratic, and interaction coefficients, respectively, $n$ is the number of factors, $i$ and $j$ are the index numbers for the factors, and $e_{i}$ is the residual error $[44,45]$.

Design-Expert 8.0 was used to analyze the experimental results and build the regression model, which helped us to predict the optimal processing parameters.

\section{Fermentation experiments}

To evaluate the effect of the carbon source on the hydrogen production, cells were cultivated using different single carbon sources or a sugar mixture at a concentration of $5 \mathrm{~g} / \mathrm{L}$ in $125-\mathrm{mL}$ serum bottles at $55^{\circ} \mathrm{C}$ for $24 \mathrm{~h}$ or $48 \mathrm{~h}$. The above-mentioned sugars included glucose, mannose, xylose, cellobiose, fructose, galactose, maltose, arabinose, lactose, sucrose, dextran, and beechwood xylan (xylooligosaccharide).

For the optimization study, the biohydrogen production was measured in $125-\mathrm{mL}$ serum bottles containing $50 \mathrm{~mL}$ of acid-hydrolyzed SCB derived under different operating conditions. The contents were used directly without sterilization and inoculated with a seed culture of $T$. aotearoense SCUT27/ $\Delta l d h$ in the late log phase of growth. The evolved gas was collected and analyzed by gas chromatography.

Batch reactor studies were carried out in a 5 - $\mathrm{L}$ Biostat B fermentor (B. Braun, Germany) containing $2 \mathrm{~L}$ of nonsterilized SCB hydrolysate. The seeds of SCUT27/ $\Delta l d h$ were inoculated into the fermentor with a ratio of $10 \%$ $(v / v)$ and then cultured at $55^{\circ} \mathrm{C}$ for $16 \mathrm{~h}$ with a stirring rate of $100 \mathrm{rpm}$. The $\mathrm{pH}$ of the culture was kept at 6.5 by automatic addition of $2.5 \mathrm{~mol} / \mathrm{L} \mathrm{NaOH}$. The liquid products were sampled at specified intervals to analyze the reducing sugars, ethanol, and organic acids by HPLC.

\section{Analytical methods}

The hydrolysate was filtered through a $0.45-\mu \mathrm{m}$ cellulose acetate membrane and analyzed by HPLC (Waters 2695, Milford, MA) for glucose, xylose, cellobiose, arabinose, acetic acid, and furfural. The culture broth after fermentation was neutralized with calcium carbonate and also filtered through a $0.45-\mu \mathrm{m}$ filter for further analysis.

The reducing sugars, ethanol, and organic acids of the hydrolysates and the fermentation broth were analyzed by HPLC using an Aminex HPX-87P column (Bio-Rad, Hercules, CA), with $1 \mathrm{mmol} / \mathrm{L} \mathrm{H}_{2} \mathrm{SO}_{4}$ as the mobile 
phase at a flow rate of $0.6 \mathrm{~mL} / \mathrm{min}$, and a refractive index detector [46]. The concentration of total phenolics in the hydrolysate was determined using a modified Folin-Ciocalteu method [47], with gallic acid (GA) as the standard. $500 \mu \mathrm{L}$ of the sample solution was mixed with $500 \mu \mathrm{L}$ of $1 \mathrm{~N}$ Folin-Ciocalteu reagent, and $1 \mathrm{~mL}$ of $20 \%$ $\mathrm{Na}_{2} \mathrm{CO}_{3}$ was added. After $10 \mathrm{~min}$ incubation at room temperature, the absorbance of the supernatant was read at $730 \mathrm{~nm}$ and compared to a standard curve of prepared GA solutions and expressed in terms of GA equivalents (grams of GA per liter).

The gas phase species from the 5-L fermentor were collected in a 30-L aluminum foil gasbag (Hua Rui Bo Yuan, Beijing, China). The gas volume was determined by water displacement and the contents of hydrogen and carbon dioxide were determined using a gas chromatograph (GC, Fuli 9790, China) equipped with a thermal conductivity detector (TCD) and a flame ionization detector (FID) through a TDX-01 column and an AE electric insulating oil analysis column [18].

The bacterial dry cell weight (DCW) was determined by a linear correlation equation from the optical density at $600 \mathrm{~nm}$ [19].

The SCB hydrolysis efficiencies $(E)$ of sulfuric acid were calculated using the following equation:

$$
[\mathrm{E}]=\frac{\sum \mathrm{S}}{1+\sum \mathrm{I}}
$$

where $\Sigma S$ is the sum of the concentrations of all sugars in the hydrolysate (glucose, xylose, cellobiose, and arabinose) and $\Sigma I$ is the sum of the inhibitor concentrations in the hydrolysate (acetic acid and total phenolics).

\section{Additional file}

Additional file 1: Sequence alignment of 16S rDNA. SCUT27,

Thermoanaerobacterium aotearoense SCUT27. Numbers 3, 4, 6, 9, and 13 are the clone numbers. Results show that the similarity of 165 rDNA gene sequences is $>99 \%$.

\section{Abbreviations}

CCR: carbon catabolite repression; DCW: dry cell weight; GC: Gas chromatograph; HMF: 5-hydroxymethyl furfural; HPLC: High performance liquid chromatography; HPR: hydrogen production rate; LSR: liquid/solid ratio; RSM: response surface methodology; SCB: sugarcane bagasse.

\section{Competing interests}

The authors declare that they have no competing interests.

\section{Authors' contributions}

$\mathrm{ZL}$ designed and carried out the hydrolysis of SCB, hydrogen fermentation, and the data analysis. MZ and XY participated in the fermentation and data analysis. JW conceived of the study and helped to draft the manuscript. SL participated in the design of the study and the data analysis, the coordination of the work, and the writing of the manuscript. All authors read and approved the final manuscript.

\section{Acknowledgements}

This research was financially supported by National Natural Science Foundation of China (21276096, 21276093), the Science and Technology Planning Project of Guangdong, China (2011B020309005, 2011A080403022), the CAS Key Laboratory of Microbial Physiological and Metabolic Engineering, Institute of Microbiology, Chinese Academy of Sciences (KLIM-201301), and the Open Project Program of Guangdong Key Laboratory of Fermentation and Enzyme Engineering, SCUT (FJ2013006). Shuang Li was funded by the Pearl River New-Star of Science \& Technology supported by Guangzhou City (2012 J2200012).

Received: 21 February 2014 Accepted: 28 July 2014

Published: 20 August 2014

\section{References}

1. Bockris JO: On hydrogen futures: toward a sustainable energy system. Int J Hydrogen Energ 2003, 28:131-133.

2. Guo XM, Trably E, Latrille E, Carrere H, Steyer JP: Hydrogen production from agricultural waste by dark fermentation: a review. Int J Hydrogen Energ 2010, 35:10660-10673.

3. IEA energy technology essentials - hydrogen production and distribution: [http://www.iea.org/techno/essentials5.pdf]

4. Saraphirom $P$, Reungsang A: Optimization of biohydrogen production from sweet sorghum syrup using statistical methods. Int J Hydrogen Energ 2010, 35:13435-13444.

5. Zhang ZY, O'Hara IM, Rackemann DW, Doherty WOS: Low temperature pretreatment of sugarcane bagasse at atmospheric pressure using mixtures of ethylene carbonate and ethylene glycol. Green Chem 2013, 15:255-264.

6. Pawar SS, Van Niel EW: Thermophilic biohydrogen production: how far are we? Appl Microbiol Biotechnol 2013, 97:7999-8009.

7. Kengen SWM, Goorissen HP, Verhaart M, Stams AJM, Van Niel EWJ, Claassen PAM: Biological hydrogen production by anaerobic microorganisms. In Biofuels. Chichester: John Wiley \& Sons, Ltd 2009, 197-221.

8. Pandey A, Soccol CR, Nigam P, Soccol VT: Biotechnological potential of agro-industrial residues. I: sugarcane bagasse. Bioresour Technol 2000, 74:69-80.

9. Basso TP, Basso TO: Gallo CR. Basso LC: Towards the production of second generation ethanol from sugarcane bagasse in Brazil. In Biomass Now Cultivation and Utilization. Edited by MatovicMD. InTech; 2013:347-354.

10. Gamez S, Gonzalez-Cabriales JJ, Ramirez JA, Garrote G, Vazquez M: Study of the hydrolysis of sugar cane bagasse using phosphoric acid. J Food Eng 2006, 74:78-88.

11. Pattra S, Sangyoka S, Boonmee M, Reungsang A: Bio-hydrogen production from the fermentation of sugarcane bagasse hydrolysate by Clostridium butyricum. Int J Hydrogen Energ 2008, 33:5256-5265.

12. Canilha L, Santos VTO, Rocha GJM, Silva JBAE, Giulietti M, Silva SS, Felipe MGA, Ferraz A, Milagres AMF, Carvalho W: A study on the pretreatment of a sugarcane bagasse sample with dilute sulfuric acid. J Ind Microbiol Biot 2011, 38:1467-1475.

13. Cheng J, Zhu M: A novel anaerobic co-culture system for bio-hydrogen production from sugarcane bagasse. Bioresour Technol 2013, 144:623-631.

14. Kaar WE, Gutierrez CV, Kinoshita CM: Steam explosion of sugarcane bagasse as a pretreatment for conversion to ethanol. Biomass Bioenergy 1998, 14:277-287.

15. Laser M, Schulman D, Allen SG, Lichwa J, Antal MJ, Lynd LR: A comparison of liquid hot water and steam pretreatments of sugar cane bagasse for bioconversion to ethanol. Bioresour Technol 2002, 81:33-44.

16. Rocha GJM, Goncalves AR, Oliveira BR, Olivares EG, Rossell CEV: Steam explosion pretreatment reproduction and alkaline delignification reactions performed on a pilot scale with sugarcane bagasse for bioethanol production. Ind Crop Prod 2012, 35:274-279.

17. Cardona CA, Quintero JA, Paz IC: Production of bioethanol from sugarcane bagasse: status and perspectives. Bioresour Technol 2010, 101:4754-4766.

18. Li S, Lai C, Cai Y, Yang X, Yang S, Zhu M, Wang J, Wang X: High efficiency hydrogen production from glucose/xylose by the Idh-deleted Thermoanaerobacterium strain. Bioresour Technol 2010, 101:8718-8724.

19. Yang X, Lai Z, Lai C, Zhu M, Li S, Wang J, Wang X: Efficient production of L-lactic acid by an engineered Thermoanaerobacterium aotearoensewith broad substrate specificity. Biotechnol Biofuels 2013, 6:124. 
20. Ren N, Cao G, Wang A, Lee D-J, Guo W, Zhu Y: Dark fermentation of xylose and glucose mix using isolated Thermoanaerobacterium thermosaccharolyticum W16. Int J Hydrogen Energ 2008, 33:6124-6132.

21. Lo YC, Lu WC, Chen CY, Chang JS: Dark fermentative hydrogen production from enzymatic hydrolysate of xylan and pretreated rice straw by Clostridium butyricum CGS5. Bioresour Technol 2010, 101:5885-5891.

22. Ask M, Bettiga M, Mapelli V, Olsson L: The influence of HMF and furfural on redox-balance and energy-state of xylose-utilizing Saccharomyces cerevisiae. Biotechnol Biofuels 2013, 6:22.

23. Laopaiboon $P$, Thani A, Leelavatcharamas V, Laopaiboon L: Acid hydrolysis of sugarcane bagasse for lactic acid production. Bioresour Technol 2010, 101:1036-1043.

24. Thomsen AB, Schmidt AS: Further development of chemical and biological processes for production of bioethanol: optimisation of pre-treatment processes and characterisation of products. Risoe National Lab: Roskilde (Denmark); 1999.

25. Aguilar R, Ramırez JA, Garrote G, Vaazquez M: Kinetic study of the acid hydrolysis of sugar cane bagasse. J Food Eng 2002, 55:309-318.

26. Kim HK, Kim JG, Cho JD, Hong JW: Optimization and characterization of UV-curable adhesives for optical communications by response surface methodology. Polym Test 2003, 22:899-906.

27. Van Niel EWJ, Budde MAW, De Haas GG, van der Wal FJ, Claassen PAM, Stams AJM: Distinctive properties of high hydrogen producing extreme thermophiles, Caldicellulosiruptor saccharolyticus and Thermotoga elfii. Int J Hydrogen Energ 2002, 27:1391-1398.

28. Mars AE, Veuskens T, Budde MAW, Van Doeveren PFNM, Lips SJ, Bakker RR, De Vrije T, Claassen PAM: Biohydrogen production from untreated and hydrolyzed potato steam peels by the extreme thermophiles Caldicellulosiruptor saccharolyticus and Thermotoga neapolitana. Int J Hydrogen Energ 2010, 35:7730-7737.

29. Evvyernie D, Morimoto K, Karita S, Kimura T, Sakka K, Ohmiya K: Conversion of chitinous wastes to hydrogen gas by Clostridium paraputrificum M-21. J Biosci Bioeng 2001, 91:339-343.

30. Wang CC, Chang CW, Chu CP, Lee DJ, Chang BV, Liao CS: Producing hydrogen from wastewater sludge by Clostridium bifermentans. J Biotechnol 2003, 102:83-92.

31. Schröder $C$, Selig M, Schönheit P: Glucose fermentation to acetate, $\mathrm{CO}_{2}$ and $\mathrm{H}_{2}$ in the anaerobic hyperthermophilic eubacterium Thermotoga maritima: involvement of the Embden-Meyerhof pathway. Arch Microbiol 1994, 161:460-470.

32. Wu X, Li Q, Dieudonne M, Cong Y, Zhou J, Long M: Enhanced $\mathrm{H}_{2}$ gas production from bagasse using adhE inactivated Klebsiella oxytoca HP1 by sequential dark-photo fermentations. Bioresour Technol 2010, 101:9605-9611.

33. Plangklang P, Reungsang A, Pattra S: Enhanced bio-hydrogen production from sugarcane juice by immobilized Clostridium butyricumon sugarcane bagasse. Int J Hydrogen Energ 2012, 37:15525-15532.

34. Kuen-Sheng W, Jung-Hsing C, Yu-Hsiang H, Shir-Ly H: Integrated Taguchi method and response surface methodology to confirm hydrogen production by anaerobic fermentation of cow manure. Int J Hydrogen Energ 2013, 38:45-53.

35. Reungsang A, Sreela-or C: Bio-hydrogen production from pineapple waste extract by anaerobic mixed cultures. Energies 2013, 6:2175-2190.

36. Ren NQ, Cao GL, Guo WQ, Wang AJ, Zhu YH, Liu BF, Xu JF: Biological hydrogen production from corn stover by moderately thermophilic Thermoanaerobacterium thermosaccharolyticum W16. Int J Hydrogen Energ 2010, 35:2708-2712.

37. Vinuselvi P, Kim MK, Lee SK, Ghim CM: Rewiring carbon catabolite repression for microbial cell factory. BMB Rep 2012, 45:59-70.

38. Vinuselvi P, Park JM, Lee JM, Oh K, Ghim C-M, Lee SK: Engineering microorganisms for biofuel production. Biofuels 2011, 2:153-166.

39. Agrawal M, Mao Z, Chen RR: Adaptation yields a highly efficient xylose-fermenting Zymomonas mobilis strain. Biotechnol Bioeng 2011 108:777-785.

40. Karhumaa K, Wiedemann B, Hahn-Hagerdal B, Boles E, Gorwa-Grauslund MF: Co-utilization of L-arabinose and D-xylose by laboratory and industrial Saccharomyces cerevisiae strains. Microb Cell Fact 2006, 5:18.

41. Vinuselvi $P$, Lee SK: Engineering Escherichia coli for efficient cellobiose utilization. Appl Microbiol Biotechnol 2011, 92:125-132.

42. Montgomery DC: Design and Analysis of Experiments. Hoboken, NJ: John-Wiley \& Sons, Inc.; 2012
43. Myers RH, Montgomery DC, Anderson-Cook CM: Response Surface Methodology: Process and Product Optimization Using Designed Experiments. 3rd edition. New York: Wiley; 2008

44. Ghosh D, Sobro IF, Hallenbeck PC: Optimization of the hydrogen yield from single-stage photofermentation of glucose by Rhodobacter capsulatus JP91 using response surface methodology. Bioresour Technol 2012, 123:199-206.

45. Ghosh D, Sobro IF, Hallenbeck PC: Stoichiometric conversion of biodiesel derived crude glycerol to hydrogen: response surface methodology study of the effects of light intensity and crude glycerol and glutamate concentration. Bioresour Technol 2012, 106:154-160.

46. Ehrman $\mathrm{Cl}$, Himmel ME: Simultaneous saccharification and fermentation of pretreated biomass: improving mass balance closure. Biotechnol Tech 1994, 8:99-104.

47. Kujala TS, Loponen JM, Klika KD, Pihlaja K: Phenolics and betacyanins in red beetroot (Beta vulgaris) root: distribution and effect of cold storage on the content of total phenolics and three individual compounds. J Agr Food Chem 2000, 48:5338-5342.

doi:10.1186/s13068-014-0119-5

Cite this article as: Lai et al:: Optimization of key factors affecting hydrogen production from sugarcane bagasse by a thermophilic anaerobic pure culture. Biotechnology for Biofuels 2014 7:119.

\section{Submit your next manuscript to BioMed Central and take full advantage of:}

- Convenient online submission

- Thorough peer review

- No space constraints or color figure charges

- Immediate publication on acceptance

- Inclusion in PubMed, CAS, Scopus and Google Scholar

- Research which is freely available for redistribution

Submit your manuscript at www.biomedcentral.com/submit
C) Biomed Central 